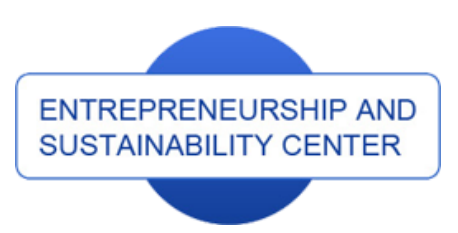

Publisher

http://jssidoi.org/esc/home

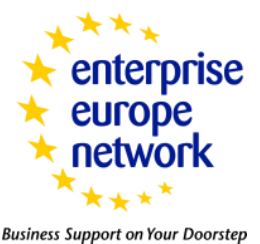

Business Support on Your Doorstep

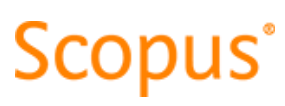

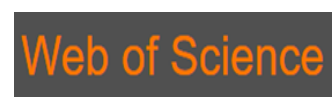

1) Clarivate

Analytics

\title{
REPUTATIONAL RISKS, VALUE OF LOSSES AND FINANCIAL SUSTAINABILITY OF COMMERCIAL BANKS
}

\author{
Natalia Kunitsyna $^{1}$, Igor Britchenko ${ }^{2}$, Igor Kunitsyn ${ }^{3}$ \\ ${ }^{1,3}$ North-Caucasus Federal University, Pushkin str. 1, 355 009, Stavropol, Russian Federation \\ ${ }^{2}$ Faculty of Technical and Economic Sciences, \\ State Higher Vocational School Memorial of Prof. Stanislaw Tarnowsk in Tarnobrzeg, \\ Henryka Sienkiewicza str. 50, 39 400, Tarnobrzeg, Poland \\ E-mails:1ㅁatkun2004@mail.ru; ${ }^{2}$ ibritchenko@gmail.com; ${ }^{3}$ kunitsyn92@mail.ru
}

Received 20 February 2018; accepted 10 May 2018; published 30 June 2018

\begin{abstract}
Currently, under the conditions of permanent financial risks that hamper the sustainable economic growth in the financial sector, the development of evaluation and risk management methods both regulated by Basel II and III and others seem to be of special importance. The reputation risk is one of significant risks affecting reliability and credibility of commercial banks. The importance of reputation risk management and the quality of their assessment remain relevant as the probability of decrease in or loss of business reputation influences the financial results and the degree of customers', partners' and stakeholders' confidence. By means of imitating modeling based on Bayesian Networks and the fuzzy data analysis, the article characterizes the mechanism of reputation risk assessment and possible losses evaluation in banks by plotting normal and lognormal distribution functions. Monte-Carlo simulation is used to calculate the probability of losses caused by reputation risks. The degree of standardized histogram similarity is determined on the basis of the fuzzy data analysis applying Hamming distance method. The tree-like hierarchy based on the OWA-operator is used to aggregate the data with Fishburne's coefficients as the convolution scales. The mechanism takes into account the impact of criteria, such as return on equity, goodwill value, the risk assets ratio, the share of the productive assets in net assets, the efficiency ratio of interest bearing liabilities, the risk ratio of credit operations, the funding ratio and reliability index on the business reputation of the bank. The suggested methods and recommendations might be applied to develop the decision-making mechanism targeted at the implementation of reputation risk management system in commercial banks as well as to optimize risk management technologies.
\end{abstract}

Keywords: reputation risks; commercial banks; business reputation; sustainable development; value of losses; economic modeling; risk level

Reference to this paper should be made as follows: Kunitsyna, N.; Britchenko, I.; Kunitsyn, I. 2018. Reputational risks, value of losses and financial sustainability of commercial banks, Entrepreneurship and Sustainability Issues 5(4): 943-955. http://doi.org/10.9770/jesi.2018.5.4(17)

JEL Classifications: E44, E47, F37 


\section{Introduction}

In the era of dynamic transformations in the financial sector of economy, tightening of requirements towards credit institutions and strengthening of competitive struggle among them make the issues of bank risk management, which include not only traditional forms of risks - credit, market, operational, liquidities, but reputation as well, more urgent (Dong et al., 2014; Vasylchak and Halachenko, 2016; Strielkowski et al., 2016; Masood et al., 2017). This can be explained by possible losses due to non-compliance with the legislation requirements, the absence of the mechanisms allowing the banks to reconcile the conflict of interests efficiently, the disability to counteract legalization (laundering) of the criminal income and other illegal activities, the drawbacks of the risk management, the negative information in the mass media, the rating downgrade and the loss of positive business image and trust from clients and partners, etc. (see e.g. Janda et al., 2013; Mostenska, 2015; Jiroudková et al., 2015; Štreimikienė et al., 2016; Host'ovecký and Poláčik, 2016; Simionescu et al., 2016; Moyseyenko and Ryvak, 2016; Andreeva et al., 2017; Tvaronavičienė, 2018).

Our novel approach to the market analysis of banking services and the main tendencies of its development is an important condition for revealing reputation threats, factors and causes of reputation risks. So, the modeling of the losses and risk level are efficient tools which enable risk management divisions to make decisions on further strategy.

\section{Theoretical Framework and Methodology}

According to standards of the international banking, every commercial bank has to develop the information security threat model which would include the description of threat sources, the vulnerabilities used by threats, methods and objects of the threat implementation, possible loss types (for example, confidentiality, integrity or assets availability) and scales of potential damage. These recommendations suggest the development of fullfledged risk model on the scenario-based analysis. The threat and violator model assess certain sources of threats (risk factors), which can cause damage to the organization with the vulnerabilities existing in this element, with each asset (Goh et al. 2015; Abrham et al., 2015; Strielkowski and Höschle, 2016; Zielińska, 2016).

In addition, the violator model includes the description and classification of violators, their experience, knowledge, resources available for threat implementation, their possible incentives and methods of threat implementation. Threat model is the characteristic of actual threat sources, methods of their implementation, objects suitable for threat implementation, types of possible losses and scales of potential damage (Evans et al., 2014; Amel-Zadeh et al., 2017).

It is important to establish the acceptable risk level, the expected damage which the organization in the particular time and particular situation will be ready to handle. The plan outlining one of the possible methods of withstanding each of the unacceptable risks: transfer of risk to the third parties (for example, insurance company); risk aversion (for example, by abandoning risk-bearing activities); conscious acceptance of risk; development of risk-reducing requirements should be developed.

Furthermore, the qualitative and quantitative evaluation based on threat probability caused by existing and (or) potential sources of threats in threat and violator model and severity of their consequences should be offered. A similar approach can be applied to reputation risks as well. Given limited techniques of their assessment and the need to combine quantitative and qualitative methods, the approach which allows their combination alongside with expert evaluation and statistical information on the value of losses as well as modeling of cause and effect 
relationships would be the most appropriate. The development of causal models, the use of Bayesian Belief network in particular, could become the best solution of this problem.

Bayesian networks are graph models of the probabilistic and cause $\leftrightarrow$ effect relationships between variables in statistical information modeling which combine empirical frequencies of various values, subjective estimate of "expectations" and theoretical concepts of mathematical probabilities of various effects from aprioristic information.

Therefore, one can conclude that the probability of top $R$ in various conditions $\left(R_{k}\right)$ depends on conditions $\left(n_{i}, S_{j}\right)$ tops $n$ and $S$ and is calculated by the formula (1):

$$
p\left(R_{k}\right)=\sum_{i} \sum_{j} p\left(R_{k} \mid n_{i} S_{j}\right) \times p\left(n_{i} \mid S_{j}\right)
$$

where $p\left(R_{k} \mid n_{i} S_{j}\right)$ is the probability of $R_{k}$ condition depending on conditions $n_{i}, S_{j}$. As the events represented by tops $n$ and $S$ are independent, as yielde in (2):

$$
p\left(R_{k} \mid n_{i}, S_{j}\right)=p\left(n_{i}\right) * p\left(S_{j}\right)
$$

Therefore, the frequency of losses will be influenced, in its turn, by the frequency of threat impact which depends on the level of control (the degree of the risk controlled by the bank) and the threat capacity which is often out of control, while reputation assets and the degree of their vulnerability will affect the value of losses

In this case, in order to calculate tops $n$ and $S$, we use the same formula as for $p\left(R_{k}\right)$. Then we can express this as follows (see (3) and (4)):

$$
\begin{aligned}
& p\left(n_{i}\right)=\sum_{m} \sum_{n} p\left(n_{i} \mid A_{\text {Im }}, B_{1 n}\right) \times p\left(A_{\text {Im }}\right) \times p\left(B_{1 n}\right) \\
& p\left(S_{j}\right)=\sum m \sum n p\left(S_{j} \mid A_{2 m}, B_{2 n}\right) \times p\left(A_{2 m}\right) \times p\left(B_{2 n}\right)
\end{aligned}
$$

From formulas (3) and (4) it is obvious that $R$ conditionally does not depend on $A_{1}, A_{2}, B_{1}, B_{2}$ as there are no arrows which directly connect these tops. Therefore, the directed acyclic graph possesses the following properties:

- each top represents the event described by a random variable which can have several conditions;

- all tops connected with the parent variable can be defined by means of conditional probability tables or conditional probability function;

- for the tops which are not connected with the "parent", the probabilities of conditions are unconditional (marginal).

Therefore, the tops represented by accidental variables and the ribs represented by probabilistic dependences can be defined by means of the probability conditional table which includes probabilities of these top conditions depending on the value of their "parents".

The benefit of this approach is the possibility to assess some risk events by applying Bayes's theorem (according to experts' knowledge only), and others by plotting cumulative distribution function based on empirical data on losses if the latter are sufficient for modeling.

As the development of Bayesian network for the risks assessment is labor-consuming, it can be used for the most significant risk factors and the most valuable and highly risk-sensitive assets. 
Threat sources and possible risk events, which are supplemented with models' violators, are the basic elements of Bayesian network concepts (Zinkevich and Shtatov, 2007). Moreover, the model should include the events which can arise as a consequence of risk implementation in bank assets. In this case, the bank suffers its main losses as the greatest damage to bank is caused by the related interruption or violation of business processes relevant for the implementation of the bank mission rather than by the risk factors.

Having plotted the directed graph, the authors assessed the concepts included in it: the probability of risk events and the value of related losses. The first indicator can be specified in a Bayesian network either as a continuous distribution function or as a table of probabilities, i.e. as discrete probabilities.

As continuous functions of distribution can be applied only in rare instances given insufficient empirical data, discrete distributions can be considered as the most appropriate. Absolute probability of each possible outcome should be specified for the concepts without entering arrows on the graph (for example, the events which are risk factors). For the concepts which are influenced by other concepts, it is relevant to specify the conditional probability for each combination of the related concepts. The task is easier to achieve if concepts are identified correctly, i.e. all types of losses are revealed, and there are no irrelevant ones (Zinkevich and Shtatov, 2007). Thus, at the first level of classification, the effects should be grouped according to the changes in reputation assets: for intangible assets - violation of integrity, availability, confidentiality, for tangible assets - the damage, from the complete loss of an asset to the interruption of the business process for the short period of time. It is possible to apply scoring as well. At the second level of loss classification, the following criteria can be considered: lost profit; penalties; loss of employees' working hours, labour productivity decline; reputation loss, etc. Such two-level classification allows us to compare damage with the cost assessment to manage risks.

In some systems which realize Bayesian Belief network the Noisy or Gate method can be used to simplify the calculating process. It is based on the fact that the top $R$ can be conditionally independent of a number of tops $A_{i}$ where $i=1,2 \ldots, n$. This method could be applied to simplify the assessment of probabilities which have to be used in the tables of conditional probabilities (see (5)):

$$
p\left(R \mid A_{1}, A_{2}, \ldots A_{n}\right)=1-\prod^{n}{ }_{i=1}\left(1-p\left(R \mid A_{i}\right)\right)
$$

It allows users to estimate only $p\left(R \mid A_{l}\right), p\left(R \mid A_{2}\right) \ldots p\left(R \mid A_{n}\right)$, which will lead to the estimation of $p\left(R \mid A_{1}, A_{2} \ldots A_{n}\right)$. Fuzzy and multiple descriptions or the fuzzy data tools should also be used in reputation risk modeling (Nedosekin, 2004a). As the histogram is a mathematical object of the following type (6):

$$
G=\{X, N, \Delta, Z\}
$$

where $X=\left[x_{\min }, x \max _{\text {ax }}\right]$ is the indicator interval for the analysis;

$N$ is the number of histogram bins;

$\Delta=\left(x_{\max }-x_{\min }\right) / N$ is the histogram step;

$Z$ is the vector of the number of quasi-statistics matching the corresponding bin of the histogram with dimension $N$,

As we have used the normal distribution, in the rated histogram vector $Z$ is replaced with vector (see (7)):

$$
Z_{i}=Z_{i} / \max _{t} Z_{i} i=1, \ldots N
$$


According to the fuzzy-set theory, it is possible to assess the measure of rated histograms similarity by the Hamming distance (Hamming, 1950; Ayala, 2012). In this case, similar histograms have similarity measure 0, and dispersing histograms have measure 1 , so the standard 01-carrier is the criterion carrier.

As a rule, the criterion of similarity is given linguistic interpretation in the form of a pentascale: VL - very low; $\mathrm{L}$ - low; $\mathrm{M}$ - medium; $\mathrm{H}$ - high; $\mathrm{VH}$ - very high.

The objective of the research is to determine risks and losses in linguistic interpretation according to a pentascale where each verbal element corresponds to a fuzzy number. In case of the standard pentascale determined on 01carriers, $\mathrm{x}$-coordinates of neutral points on 01 -carriers are $(0.2 ; 0.4 ; 0.6 ; 0.8)$ (Nedosekin, 2004b).

Therefore, if very low value of factor $x$ is within the range between 0 and 0.25 , but the expert is not confident in the assessment, he specifies that in case of $x>0.25$ the level is not very low, and in case of $x<0.15$ the level is very low. Then, interval $[0.15 ; 0.25]$ will be the uncertainty area in the assessment which can be described by an inclined rib of the trapezoid fuzzy number. The advantage of such description is the neutral point in the middle of the uncertainty interval and a steady decrease in expert confidence in classification with the simultaneous growth in $x$ (Barth et al., 2017).

Trapezoid numbers are called the fuzzy interval as a trapezoid number could be described with the following statement: "low parameter value of $x$ fluctuates somewhere from 0.2 to 0.4 ". The word "somewhere" means that the left end of the interval equals approximately 0.2 , and the right is about 0.4 , and this approximate movement is interpreted by a trapeze rib with the corresponding inclination.

The next step is plotting the pentascale on the basis of the normal distribution histogram, the calculation of the average value $\mu$ and the mean-square deviation $\sigma$. So, the set of five nodes of the five-level qualifier is as expressed in the following system (8):

$$
\begin{aligned}
& \mu_{1}=\mu-t_{1} \sigma, \\
& \mu_{2}=\mu-t_{2} \sigma, \\
& \mu_{3}=\mu, \\
& \mu_{4}=\mu+t_{2} \sigma, \\
& \mu_{5}=\mu+t_{1} \sigma,
\end{aligned}
$$

where $t_{i}$ are coefficients (Student's distribution).

For each node, the factor level is identified with absolute confidence. For example, point $\mu_{1}$ corresponds to a very low factor level (VL), $\mu_{2}-$ to low (L), etc.

If the interval $\left[\mu_{i}, \mu_{i+1}\right]$ is divided into three areas: an area of absolute confidence, an area of lower confidence and an area of absolute uncertainty, the length of these three areas is the following proportion: $1: r: 1$, where parameter $r \geq 0$ means the degree of uncertainty. In case of a standard pentascale on 01-carriers, $r=2$, therefore the choice of $r$ remains at the discretion of developers. 


\section{Analysis of empirical model}

We have calculated the frequency of losses and their value as a result of risks impact on business reputation of the banks under investigation, which is illustrated by the example below. The directed graph has eight tops according to the integrated group of possible losses from implementation of reputation risks on eight most significant criteria (Table 1).

Table 1. The value of expected losses as a result of risks impact on business reputation of Bank B

\begin{tabular}{|l|c|c|}
\hline Type of threats & Losses frequency, \% & $\begin{array}{l}\text { Expected value of } \\
\text { losses, cur. un. }\end{array}$ \\
\hline 1. Obtaining credit with falsified documents & 1.333 & $8,316,521.2$ \\
\hline 2. Partial or complete loss of the credit collateral & 15.09 & $94,145,765.5$ \\
\hline 3.Violation of the loan restructuring order & 7.549 & $47,097,838.5$ \\
\hline 4. Failures in IT systems & 7.735 & $48,258,283.4$ \\
\hline 5. Money shortage in cash machines & 1.28 & $7,985,856.8$ \\
\hline $\begin{array}{l}\text { 6. Miscalculations and money shortage in a collector bag to } \\
\text { be sent to the payment processing center }\end{array}$ & 23.906 & $149,148,354.5$ \\
\hline 7. Cash plundering from the cash desk by an employee & 41.233 & $257,250,652.6$ \\
\hline 8. Other & 1.874 & $11,691,793.5$ \\
\hline Total & 100 & $623,895,066$ \\
\hline Arithmetic average & - & $77,986,887$ \\
\hline Mean square deviation & - & $87,380,635$ \\
\hline
\end{tabular}

The calculation of losses probability from reputation risks implementation in Bank B was carried out through Monte-Carlo simulation, normal (Gaussian) distribution.

For modeling, lognormal distribution can be used, assuming that each following value has less value than in the previous period.

The normal distribution of the values which are within the range between 10 million currency units (minimum) and 260 million currency units (maximum), according to the data on possible losses from operating mistakes by employees (table 1), is represented in Figure 1. 


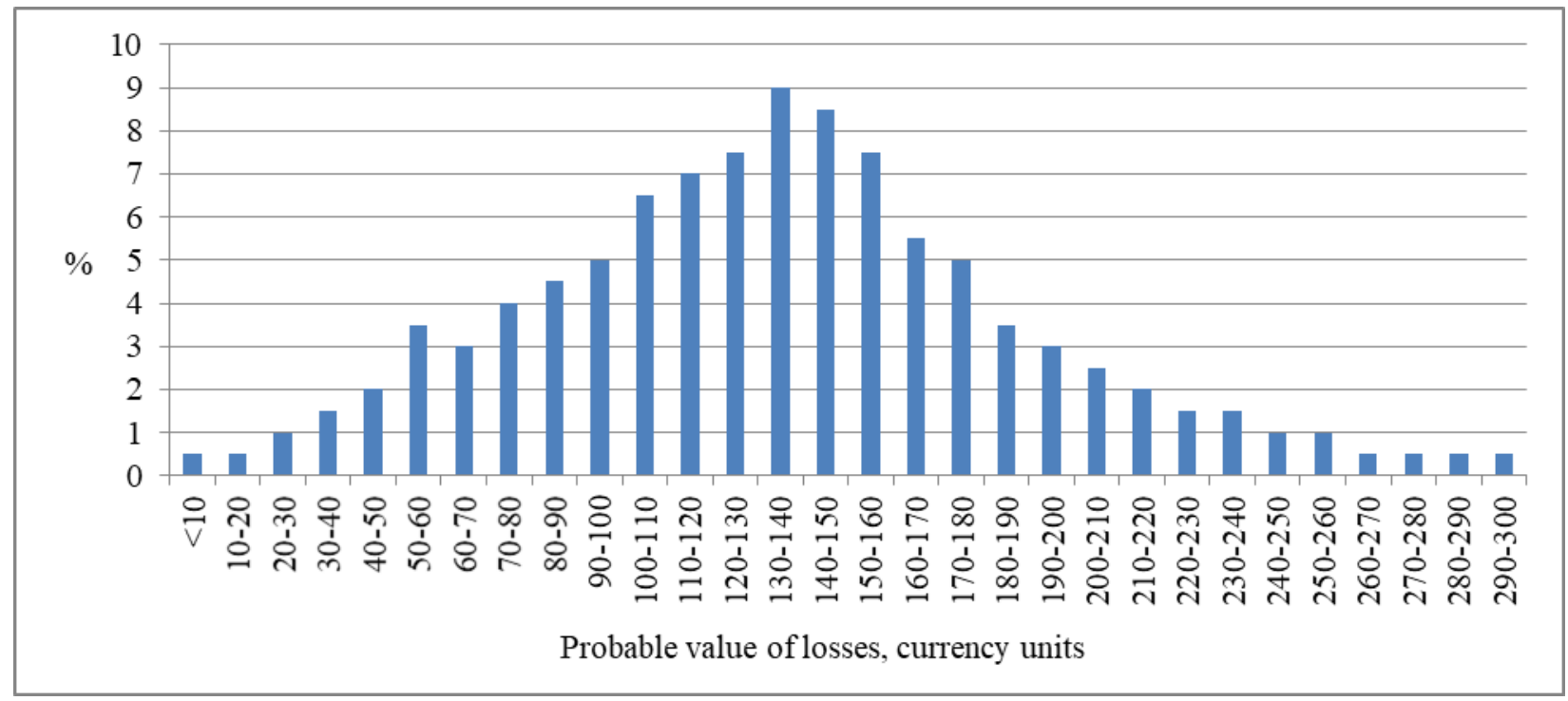

Fig. 1. Distribution of losses probability as a result of operating mistakes by employees, $\%$ Source: Own results

As we have used only 100 random values, the distribution appears to be quite asymmetric. Nevertheless, $97.5 \%$ of values are within the range between 10 and 260 million currency units. To increase Monte Carlo simulation accuracy at the following stage, we have created 10,000 scenarios on all risk groups. The bar chart of the total losses distribution is represented in Figure 2.

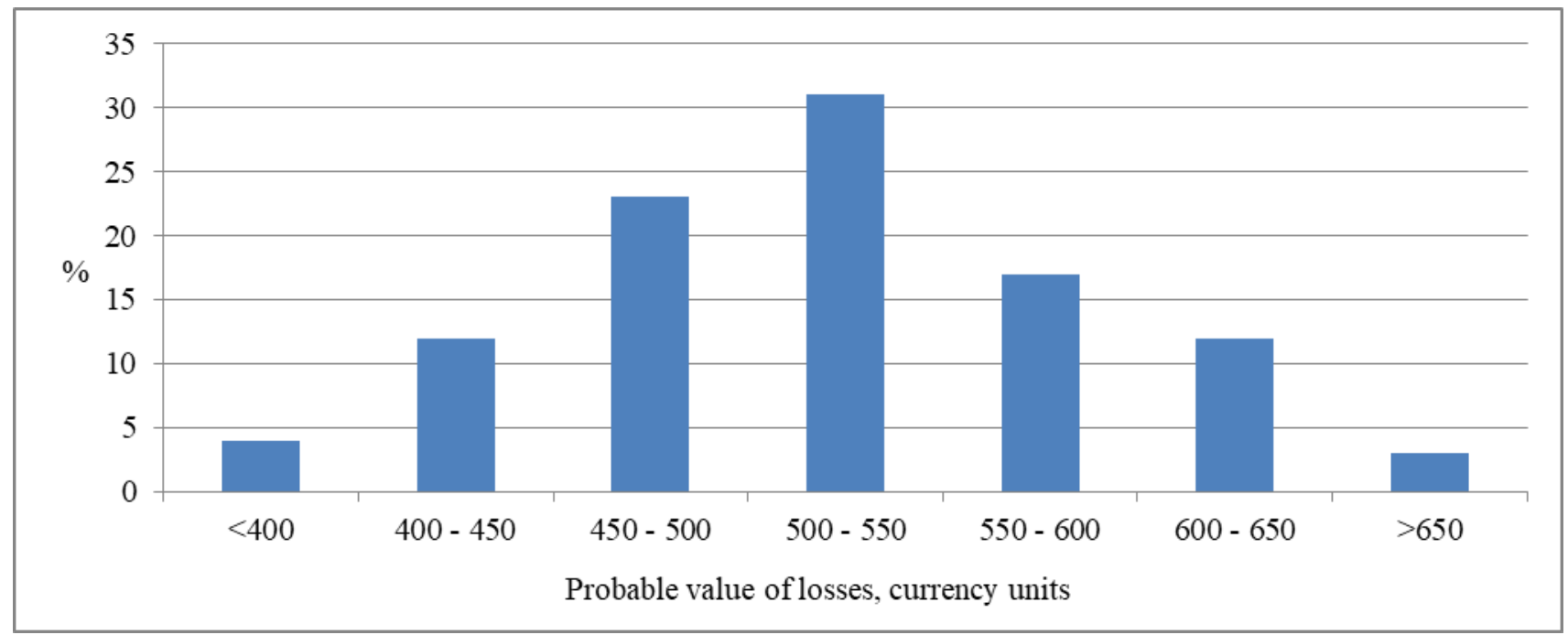

Fig. 2. Distribution of total losses probability, in \%

$$
\text { Source: Own results }
$$




\section{Discussion of the model results}

About $16 \%$ of risk implementation lead to losses of less than 450 million currency units. It means that the probability of losses is $16 \%$, which represents a substantial risk. Applying fuzzy data method (figure 4), according to the histogram for the carrier $x=[0,300]$ we have calculated: $\mu=150, \sigma=90.92$. As far as $r=1$, then all areas (confidence - lowered confidence - uncertainty) have equal length.

Histogram's carrier 35 is considered to be very low in terms of expert method while carrier 265 is very high. Consequently, $\mathrm{t}_{1}=(150-35) / 90.92=(265-150) / 90.92=1.265$. Carrier 55 is low, therefore $\mathrm{t}_{2}=(150-55) /$ $90.92=1.044$. Respectively, $\mu_{4}=\mu+\mathrm{t}_{2} \sigma=150+1.044 * 90.92=245$.

Thus, the intervals of absolute confidence areas are as following:

VL: $[0 ; 35+(55-35) / 3]=[0 ; 41.67]$

$\mathrm{L}:[55-(55-35) / 3 ; 55+(150-55) / 3]=[48.33 ; 86.67]$;

M: $[150-(150-55) / 3 ; 150+(245-150) / 3]=[118.33 ; 181.67]$;

$\mathrm{H}:[245-(245-150) / 3 ; 245+(265-245) / 3]=[213.33 ; 251.67]$;

VH: $[265-(265-245) / 3 ; 300]=[258.33 ; 300]$.

Respectively, using nodes and absolute confidence intervals, the pentascale represented in Figure 3 could be plotted.

Fig. 3. Pentascale for the histogram of losses probability caused by cash plundering by employees

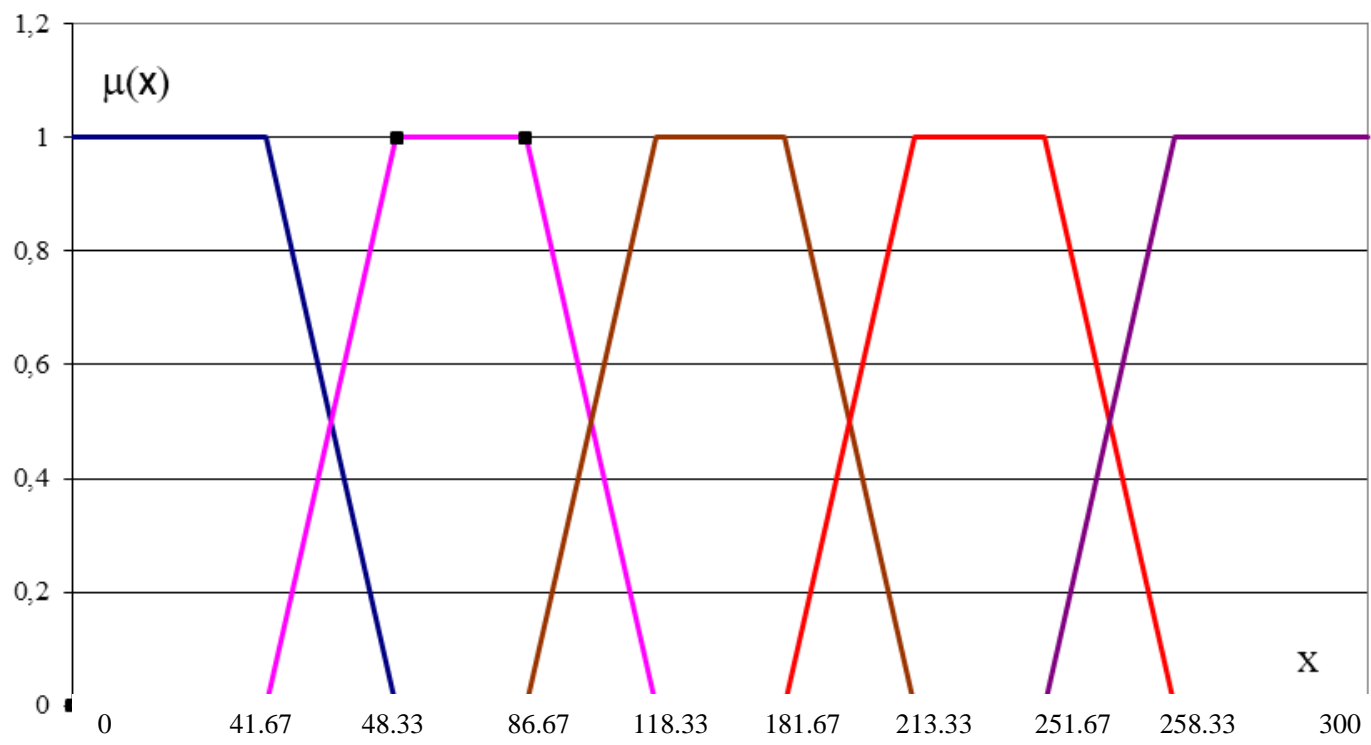

Source: Own results 
Therefore, interpreting the values, it is possible to make a conclusion that the value of losses from 0 to 41.67 million currency units is very low for the bank under investigation, from 48.33 to 86.67 million currency units is low, from 118.33 to 181.67 is medium, from 213.33 to 251.67 is high and over 258.33 is very high.

According to figure 3 representing the probability of the general losses distribution for the carrier $x$ equals [0, 700], $\mu$ equals 350, $\sigma$ equals 223,6. As far as $r=1$, then all areas (confidence - lowered confidence - uncertainty) have equal length.

Carrier 150 is very low, and carrier 550 is very high. Then, $\mathrm{t}_{1}=(350-150) / 223.6=(550-350) / 223.6=0.894$. Moreover, if carrier 250 is low, $\mathrm{t}_{2}=(350-250) / 223.6=0.447$. Respectively, we obtaiin $\mu_{4}=\mu+\mathrm{t}_{2} \sigma=350+$ $0.447 * 223.6=450$.

Thus, intervals of absolute confidence areas are as following:

VL: $[0 ; 150+(150-350) / 3]=[0 ; 83.33]$

$\mathrm{L}:[250-(250-150) / 3 ; 250+(350-250) / 3]=[216.67 ; 283.33]$;

M: $[350-(350-250) / 3 ; 350+(450-350) / 3]=[316.67 ; 383.33]$;

$\mathrm{H}:[450-(450-350) / 3 ; 450+(550-450) / 3]=[416.67 ; 483.33]$;

VH: $[550-(550-450) / 3 ; 700]=[516.67 ; 700]$.

Therefore, the value of losses from 0 to 83.33 million currency units is very low for the bank in question, from 216.67 to 283.33 is low, from 316.67 to 383.33 is medium, from 416.67 to 483.33 is high and over 516.67 million is very high.

We should emphasize that in the future it is possible to specify the qualifier based on additional data or conclusions as well as to move nodes and to receive new membership functions.

For further research, we applied the fuzzy-set theory. Using the two-level Bayesian network (figure 2), we have imposed preference relation system $F$ on it (9):

$$
\left.\left.\left.F=\left\{S_{l}\right\}=n ; B l\right\}=A l ; B l\right\}=A_{l}\right\}
$$

where $\}=$ means preference, and $\approx$ means indifference.

To make quantitative and qualitative risk assessment, aggregating of the data represented within tree-like hierarchy along the graph ribs should be done. The OWA (OWA - Ordered Weighted Averaging - averaging with the ordered scales) operator (Yager, 1993) is applied to aggregating, and Fishburne's ratios are the scales in rollup.

For each indicator of the second level hierarchy in decreasing preference system of $N$ alternatives Fishburne's coefficients are calculated (Trukhaev, 1981; Fishburne, 1978) by the formula expressed in (10):

$$
p_{i}=2(N-i+1) /(N+1) N \quad i=1, \ldots N
$$

where $p_{i}$ is Fishburne coefficient for indicator $x_{i}$;

$N$ is the total quantity of indicators in hierarchy, $N>0$;

$i$ is the sequence number of indicator $x_{i}$ in the group. 
In the system where $N$ alternatives are indifferent to each other, the set of equal scales is as shown in (11):

$$
p_{i}=N^{-1} \quad i=1, \ldots N
$$

At the same time, if the preference relations are the parts of the system only, then (see (12)):

$$
r_{N}=1, \quad r_{i}-1=r_{i}+1, \quad K=1+2+\ldots .+N=N(N+1) / 2
$$

where $r_{i}$ are the numerators of recursive fractions;

$K$ is the amount of numerators or the common denominator of Fishburne fractions.

That is the presented in (13):

$$
p_{i}=r_{i} / K
$$

The standard qualifier usually maps fuzzy linguistic description on the 01 -carriers by a consistent method, symmetrizing the classification nodes $(0.1 ; 0.3 ; 0.5 ; 0.7 ; 0.9)$. The values of the membership function in these nodes equal 1, and all other functions equal 0 . Experts' uncertainty in classification decreases (increases) linearly as it moves away from the node (approaching the node, respectively); at the same time the number of membership functions in all carrier points equals 1 (Nedosekin, 2004a).

Therefore, if linguistic values are known for each indicator $\left(F_{* .1} \ldots F_{* . N}\right)$ on the chosen hierarchic sublayer, and the system of Fishburne scales on the preferences-based system $F$ is calculated, the linguistic values will be calculated from ratios of membership function sets. These risk levels for the graph-based hierarchies are shown in Table 2 that follows.

Table 2. Matrix of risk level of bank B based on membership functions and Fishburne coefficients

\begin{tabular}{|l|l|c|c|c|c|c|c|}
\hline \multirow{2}{*}{ Factor } & \multirow{2}{*}{ Fishburne scales } & \multicolumn{5}{c|}{ Risk level } \\
\cline { 6 - 8 } & & & VL & L & M & H & VH \\
\hline R & Reputation risk & & & & & & \\
\hline$S$ & Value of losses & & & & & & \\
\hline B2 & Asset vulnerability & 0.428 & 0 & 0.22 & 0.78 & 0 & 0 \\
\hline A2 & Cost of reputation asset & 0.286 & 0 & 0.36 & 0.64 & 0 & 0 \\
\hline$n$ & Frequency of losses & & & & & & \\
\hline B1 & Threat capacity & 0.143 & 1 & 0 & 0 & 0 & 0 \\
\hline A1 & $\begin{array}{l}\text { Frequency of threats } \\
\text { impact }\end{array}$ & 0.143 & 1 & 0 & 0 & 0 & 0 \\
\hline
\end{tabular}

Source: Own results 
As it appears from our results, the bank's reputation risk level and the value of losses are estimated as medium. Moreover, it turns out that in spite of the low level of losses frequency depending on threat capacity and frequency of threats impact, the risk level is assessed as medium due to other factors (asset vulnerability and cost of reputation asset) prevailing in the "average" values.

\section{Conclusions and overall discussions}

In general, the sequence of the described approach is as follows: First of all, one should run a calculation of absolute probabilities of risk implementation based on the conditional probability formula allowing banks to estimate them by comparing the set of conditional probabilities and the known probabilities of risk implementation or the causes (factors) of risk implementation.

Second, calculation of each outcome probability for every risk case by consecutive movement along the networks and application of Bayes theorem along with the conditional probability formula should be applied.

Third, calculation of probable value of losses from risk implementation based on the statistics and expert methods by analogy with other organizations taking into account scale effect should be done. The value of real financial loss can be evaluated on the basis of an experts' experience or the operating losses method. Losses can be also estimated in probabilistic terms using confidential intervals or distributions. The expert method (based on the modified Delfi method) which includes the assessment of reputation relative characteristics is of greater use as it allows banks to estimate the clients outflow, the decrease in new accounts and deposits opened, etc.

Fourth, the total risk assessment should be summed up by adding up losses distributions on several risk events. Adding up should be done to calculate the expected and unexpected value of losses calculated on the basis of the arithmetic average and VaR which is the aggregative distribution of bank's risk. Such addition in Bayesian network is carried out, as a rule, by means of Monte-Carlo-simulation based on the imitation of accidental emergence of various outcomes of events-drivers which move to network entrances.

Summing up our results, it is possible to conclude that the our suggested mechanism of reputation risks assessment according to functional dependence of the bank's business reputation impacts on a number of criteria: return on equity, goodwill value, the share of uncommitted (free) resources in assets, risk assets ratio, productive assets share in net assets, efficiency ratio of interest bearing liabilities, risk ratio of credit operations, overdue debt share in total loan debt, funding ratio and reliability index on the business reputation of the bank. It is based on the combination of imitating modeling, statistical analysis and expert evaluations.

In addition, under advanced international requirements currently applied to banking, the development of evaluation and risk management methods both regulated by Basel II and III and others is of utmost importance. The reputation risk is one of significant risks affecting reliability and credibility of a bank. All in all, one can see that the suggested methods and recommendations might be applied to develop the decision-making mechanism targeted at the implementation of reputation risk management system in commercial banks as well as to optimize risk management technologies. 


\section{References}

Abrham, J.; Strielkowski, W.; Vošta, M.; Šlajs, J. 2015. Factors that influence the competitiveness of Czech rural small and medium enterprises. Agricultural Economics (Zemédělská Ekonomika) 61(10):450-460. https://doi.org/10.17221/63/2015-AGRICECON

Amel-Zadeh, A.; Barth, M. E.; Landsman, W. R. 2017. The contribution of bank regulation and fair value accounting to procyclical leverage. Review of Accounting Studies 22(3): 1423-1454. https://doi.org/10.1007/s11142-017-9410-6

Andreeva, E. L.; Karkh, D. A., Myslyakova, Y. 2017. Conceptual Approach to Forming the Basic Code of Neo-Industrial Development of a Region. Economy of Region 13(3):732-745. https://doi.org/10.17059/2017-3-8

Ayala J. 2012. Fast Propagation of Hamming and Signal Distances for Register-Transfer Level Datapaths. Integrated Circuit and System Design 1:62-67.

Barth, M. E.; Gomez-Biscarri, J.; Kasznik, R.; López-Espinosa, G. 2017. Bank earnings and regulatory capital management using available for sale securities. Review of Accounting Studies 22(4): 1761-1792. https://doi.org/10.1007/s11142-017-9426-y

Dong, M.; Ryan, S.; Zhang, X. J. 2014. Preserving amortized costs within a fair-value-accounting framework: Reclassification of gains and losses on available-for-sale securities upon realization. Review of Accounting Studies 19(1):242-280. https://doi.org/10.1007/s11142-013$\underline{9246-7}$

Evans, M. E.; Hodder, L.; Hopkins, P. E. 2014. The predictive ability of fair values for future financial performance of commercial banks and the relation of predictive ability to banks' share prices. Contemporary Accounting Research 31(1):13-44. https://doi.org/10.1111/1911$\underline{3846.12028}$

Fishburne P. 1978. The theory of usefulness for decision making. Moscow: Science. 352 p.

Goh, B. W.; Li, D.; Ng, J.; Yong, K. O. 2015. Market pricing of banks' fair value assets reported under SFAS 157 since the 2008 financial crisis. Journal of Accounting and Public Policy 34(2): 129-145. https://doi.org/10.1016/j.jaccpubpol.2014.12.002

Hamming, R. W. 1950. Error detecting and error correcting codes. Bell Labs Technical Journal 29(2):147-160. https://doi.org/10.1002/j.1538-7305.1950.tb00463.x

Host'ovecký, M.; Poláčik M. 2016. Communication skills as the competitive advantage of sellers. Czech Journal of Social Sciences, Business and Economics, 5(1), 18-26. https://doi.org/10.24984/cjssbe.2016.5.1.2

Janda, K.; Rausser, G.; Strielkowski, W. 2013. Determinants of Profitability of Polish Rural Micro-Enterprises at the Time of EU Accession. Eastern European Countryside 19: 177-217. https://doi.org/10.2478/eec-2013-0009

Jiroudková, A.; Rovná, L. A.; Strielkowski, W.; Šlosarčík, I. 2015. EU Accession, Transition and Further Integration for the Countries of Central and Eastern Europe. Economics and Sociology 8(2):11-25. https://doi.org/10.14254/2071-789X.2015/8-2/1

Mostenska, T. 2015. Informal market as a result of shadow economy. Czech Journal of Social Sciences, Business and Economics 4(2):2329. https://doi.org/10.24984/cjssbe.2015.4.2.3

Masood, O.; Aktan, B.; Gavurová, B.; Fakhry, B.; Tvaronavičienė, M., Martinkutė-Kaulienė, R.. 2017. The impact of regime-switching behaviour of price volatility on efficiency of the US sovereign debt market, Economic Research-Ekonomska Istraživanja 30(1): 1865-1881 http://dx.doi.org/10.1080/1331677X.2017.1394896

Moyseyenko, I.; Ryvak, N. 2016. Indirect taxes in the mechanism of state regulation. International Economics Letters 5(2):63-71. https://doi.org/10.24984/iel.2016.5.2.4

Nedosekin A.O. 2004a. Business risk assessment on the basis of fuzzy data. Available from the Internet: http://www.ifel.ru/content/docs/an_books/Book4.pdf 
The International Journal

ENTREPRENEURSHIP AND SUSTAINABILITY ISSUES

ISSN 2345-0282 (online) http://jssidoi.org/jesi/

2018 Volume 5 Number 4 (June)

http://doi.org/10.9770/jesi.2018.5.4(17)

Nedosekin A.O. 2004b. Complex risk assessment of bankruptcy of corporation on the basis of fuzzy descriptions. Available from the Internet: http://sedok.narod.ru/sc_group.html

Simionescu, M.; Ciuiu, D.; Bilan, Y.; Strielkowski, W. 2016. GDP and net migration in some eastern and south-eastern countries of Europe. A panel data and Bayesian approach. Montenegrin Journal of Economics 12(2):161-175. https://doi.org/10.14254/1800$\underline{5845.2016 / 12-1 / 10}$

Štreimikienè, D.; Strielkowski, W.; Bilan, Y.; Mikalauskas, I. 2016. Energy dependency and sustainable regional development in the Baltic States: A review. Geographica Pannonica, 20(2):79-87. https://doi.org/10.5937/GeoPan1602079S

Strielkowski, W.; Tumanyan, Y.; Kalyugina, S. 2016. Labour Market Inclusion of International Protection Applicants and Beneficiaries, Economics and Sociology 9(2):293-302. https://doi.org/10.14254/2071-789X.2016/9-2/20

Strielkowski, W.; Höschle, F. 2016. Evidence for economic convergence in the EU: The analysis of past EU enlargements. Technological and Economic Development of Economy 22(4): 617-630. https://doi.org/10.3846/20294913.2014.890138

Trukhayev, R.I. 1981. Decision making model in the conditions of uncertainty. Moscow: Science. 258 p.

Tvaronavičienè, M. 2018. Toward efficient policy making: forecasts of vulnerability to external global threats, Journal of Security and Sustainability Issues 7(3): 591-600. https://doi.org/10.9770/jssi.2018.7.3(18)

Vasylchak, S.; Halachenko, A. 2016. Theoretical basis for the development of resort services: regional aspect. International Economics Letters 5(2):54-62. https://doi.org/10.24984/iel.2016.5.2.3

Yager R., 1993. Families of OWA Operators. Fuzzy Sets and Systems 59(2):125-148. https://doi.org/10.1016/0165-0114(93)90194-M

Zinkevich V.A., Shtatov D.N. 2007. Information risks: analysis and quantitative assessment. Accounts Department and Banks 2:48-53.

Zielińska, A. 2016. Information is a market products and information markets. Czech Journal of Social Sciences, Business and Economics 5(4):31-38. https://doi.org/10.24984/cjssbe.2016.5.4.4

\section{Natalia Kunitsyna}

ORCID: 0000-0001-9336-8100

Igor Britchenko

ORCID: 0000-0002-9196-8740

Igor Kunitsyn

ORCID: 0000-0002-3460-8167

Register for an ORCID ID:

https://orcid.org/register

Copyright (C) 2018 by author(s) and VsI Entrepreneurship and Sustainability Center

This work is licensed under the Creative Commons Attribution International License (CC BY).

http://creativecommons.org/licenses/by/4.0/

(c) (i) Open Access 